\title{
Utility of the QT interval in predicting outcomes in patients presenting to the emergency department with chest pain.
}

\author{
Toni A de Venecia \\ Einstein Medical Center \\ Marvin Y Lu \\ Einstein Medical Center \\ Chinualumogu C Nwakile \\ Einstein Medical Center \\ Vincent M. Figueredo, M.D. \\ Thomas Jefferson University
}

Follow this and additional works at: https://jdc.jefferson.edu/cardiologyfp

Part of the Cardiology Commons

Let us know how access to this document benefits you

\section{Recommended Citation \\ de Venecia, Toni A; Lu, Marvin Y; Nwakile, Chinualumogu C; and Figueredo, M.D., Vincent M., "Utility of the QT interval in predicting outcomes in patients presenting to the emergency department with chest pain." (2015). Division of Cardiology Faculty Papers. Paper 54. \\ https://jdc.jefferson.edu/cardiologyfp/54}

This Article is brought to you for free and open access by the Jefferson Digital Commons. The Jefferson Digital Commons is a service of Thomas Jefferson University's Center for Teaching and Learning (CTL). The Commons is a showcase for Jefferson books and journals, peer-reviewed scholarly publications, unique historical collections from the University archives, and teaching tools. The Jefferson Digital Commons allows researchers and interested readers anywhere in the world to learn about and keep up to date with Jefferson scholarship. This article has been accepted for inclusion in Division of Cardiology Faculty Papers by an authorized administrator of the Jefferson Digital Commons. For more information, please contact: JeffersonDigitalCommons@jefferson.edu. 


\section{Utility of the QT interval in Predicting Outcomes in Patients Presenting to the Emergency Department with Chest Pain}

T. De Venecia ${ }^{a}$, M. Lu ${ }^{a}$, A. Dimou ${ }^{a}$, C. Nwakile ${ }^{b}$, V.M. Figueredo ${ }^{b, c}$

(a) Department of Internal Medicine, Einstein Medical Center, Philadelphia, PA

(b) Einstein Institute for Heart and Vascular Health, Einstein Medical Center, Philadelphia, PA

(c) Sidney Kimmel Medical College of Thomas Jefferson University, Philadelphia, PA

Conflict of Interest: The authors have no conflicts of interest to report

Running Title: QTc Prolongation as predictor of outcomes in patients presenting with chest pain Keywords: QT interval, Chest pain, Emergency Department, Electrocardiogram

Corresponding Author: Toni Anne De Venecia M.D.

Internal Medicine Resident, Albert Einstein Medical Center

5501 Old York Road, $3^{\text {rd }}$ Floor Klein Building

Department Internal of Medicine

Philadelphia, PA 19141

$215-456-6500$

detonian@einstein.edu 
The number of words in the abstract: 250

The number of words in the text: 1220

The number of tables and figures: 3

The number of cited references: 12 


\begin{abstract}
OBJECTIVES: To investigate whether prolongation of the heart rate-corrected QT interval (QTC) is an independent risk factor for predicting future acute coronary syndrome (ACS) occurrence or mortality in patients with at least one cardiac risk factor presenting with chest pain to the Emergency Department (ED).
\end{abstract}

BACKGROUND: QTC prolongation is associated with ventricular arrhythmias and increased mortality in patients with ACS or known coronary artery disease (CAD). In contrast, population-based studies have shown no consistent association between QTC prolongation and ACS or mortality in a population with no known CAD. The prognostic implications of QTc prolongation on clinical outcomes in patients who present to the ED with chest pain is not known.

METHODS: Single center, retrospective study in patients presenting with chest pain to the Einstein Medical Center Philadelphia ED between 2011 and 2012. Proportional hazards models were used to calculate hazard ratios for occurrence of ACS or death within 1 year. Kaplan Meier Curves were used to determine time to event for QTc low (<460 ms) versus QTc high ( $\geq 460 \mathrm{~ms})$ groups.

RESULTS: Five hundred ninety five patients met criteria. Older age, hypertension, diabetes mellitus and hyperlipidemia were more common in the QTc high group. Patients in the QTc high group were more likely to experience subsequent ACS or death (HR $8.1295 \% \mathrm{Cl}$ 4.00-16.72), even after adjusting for traditional cardiac risk factors (HR 7.68 95\% Cl 3.57-16.61). 
Conclusion: QTc prolongation at ED presentation with chest pain and at least one cardiac risk factor predicts subsequent ACS and death. 


\section{Introduction}

The International Long QT Syndrome Registry found that the risk of developing malignant arrhythmias in patients with QT prolongation is exponentially related to the length of the QT interval.[1] However, the role of the heart rate-corrected QT interval (QTc) for prognostication in a population with no known coronary artery disease $(C A D)$, versus those with $C A D$, is not known.[2,3,4,5,6,7] The availability and widespread use of digitized electrocardiographic recordings for patients presenting with chest pain to the ED provides readily accessible data in determining the QTc interval.

Retrospective studies found that QTc prolongation is associated with a higher risk of morbidity and mortality in patients with known CAD.[1] QTc prolongation has been associated with ventricular arrhythmias and increased mortality in ACS patients.[11,12] In contrast, population-based studies have shown no consistent association between QTc prolongation and occurrence of ACS or mortality in a healthy asymptomatic population.[2,3,4,5,6,7,13] Further, the effect of QTc prolongation on clinical outcomes of patients who present to the ED with chest pain is not known. The objective of this study was to investigate whether QTc prolongation is an independent risk factor for predicting ACS occurrence or mortality in patients, with at least one cardiac risk factor, presenting to the ED with chest pain. . 


\section{Methods}

This was a retrospective review of medical records including all patients 18 years or older presenting to the Einstein Medical Center Philadelphia ED between June 2011 and June 2012 with chest pain, who had known cardiac risk factors, but no prior CAD history. Cardiac risk factors included hypertension, dyslipidemia, family history of CAD, diabetes mellitus, smoking and obesity ( body mass index $[\mathrm{BMl} \geq 26]$ ). This study was approved by the Einstein Medical Center Institutional Review Board (IRB).

Patients taking medications that prolong the QT interval (e.g. methadone, specific antiarrhythmics, antihistamines, antibiotics and psychotropics), had electrolyte abnormalities (hypokalemia, hypocalcemia), had central nervous system injury, known CAD and those with baseline atrial fibrillation or bundle branch block were excluded.

Demographic data including age, gender, BMI, hypertension, hyperlipidemia, diabetes mellitus, family history of premature $\mathrm{CAD}$ and smoking status were collected from patient charts (Table 1). QTc intervals were collected from the index electrocardiogram and were classified as high or low based on a cut point set of 460 msec (cut off used in majority of prior studies) $[9,11,12]$. The QT interval was corrected for heart rate in surface ECG using Bazett's formula. Electronic medical records of Einstein Medical Center Philadelphia were used to access subsequent ACS diagnoses. Patients were followed for a mean of 1 year for subsequent ACS diagnosis or death (Social Security Death Index), whichever happened first. Social security death index was used to assess occurrence of death within 1 year after presentation to the ED. 
Data analysis: Patient groups were compared with and without QT prolongation with regards to each of the demographic variables using Student t-tests for quantitative variables and chi squared tests for categorical variables. Hazards ratio were calculated for death or ACS within one year. Proportional hazards model/cox model was constructed to adjust for the effect of demographics on mortality and ACS within one year, and to calculate the adjusted hazards ratios. Kaplan Meier curve was used to estimate time to event for the QTc low and high groups. Log rank $p$ values were used to compare curves. JMP 10 (SAS, Cary, NC) was used for all statistics. A p value of 0.05 or less was considered statistically significant. 


\section{Results}

Of 700 charts reviewed, 105 charts were excluded: fifty eight due to absence of any cardiac risk factor, 20 due to absence of a baseline ECG at the ED visit, 12 had atrial fibrillation or bundle branch block, and 13 had electrolyte abnormalities or use of drugs known to prolong QTc. Mean follow up was 1 year from index ED visit. Demographic variables were compared between groups with and without QT prolongation (Table IA). Fifty nine of 595 (10\%) patients studied experienced an ACS event during the index hospitalization and were not included in outcome measures. Patients with QTc $>460$ had a higher incidence of older age ( $>60$ years old), hypertension, diabetes mellitus and hyperlipidemia. Multivariate analysis for the composite of ACS and mortality was performed to account for these significant demographic differences (Table IB). Multivariate analysis demonstrated that a prolonged QTC was associated with a marked increase in risk of having ACS or death within 1 year after ED presentation. As shown in Figure. 1, the Kaplan Meier survival plot shows that ACS and mortality occurrence appears to increase at 4 months after index presentation with chest pain in the ED. 


\section{Discussion}

The major finding of this study was that a prolonged QTc interval was associated with a more than seven-fold increased risk of ACS or death within 1 year of ED presentation for chest pain in patients with at least one cardiac risk factor. This was independent of other cardiac risk factors.

Epidemiological studies evaluating total and cardiovascular mortality associated with QTc prolongation have yielded conflicting results. The Framingham study failed to show an association of baseline QTc prolongation with total mortality, sudden death, or coronary mortality in a healthy population.[8] In contrast, the Cardiovascular Health Study, showed an association between a QTc $>450 \mathrm{~ms}$ and total mortality in a healthy population. In the Strong Heart Study, a QTc $>460$ ms was associated with a two-fold increased risk of cardiac and total mortality in a healthy population.[9] In the Rotterdam Study, QTc prolongation $>440 \mathrm{~ms}$ was associated with an increased risk of total and cardiovascular mortality, this time with an elderly population.[2] A recent study of Beinart et al, found that QTc of $>460$ or each 10 ms increase in the QTc with patients not known to have CAD was associated with increased risk for future rate of strokes, cardiovascular events and heart failure readmissions.[12] In studies by Gadelata et al and Jiménez-Candil et al, prolongation of QTc interval (>458 msec) in patients with ACS on admission ECG was an independent predictor of cardiovascular risk, defined as recurrence of ACS within 30 days and at 1 year of follow up.[10,11] In their studies they 
found a positive correlation between prolonged QTc intervals and cTnT levels. To date, no study has examined the prognostic value of the QTc interval in patients presenting to the ED with chest pain. Thus, the present study extends the findings summarized above, in that patients presenting with chest pain to the ED with at least one cardiac risk factor are at increased risk for ACS events and all cause death within one year if their QTc is greater than $460 \mathrm{~ms}$.

This is the first study to address a population of patients presenting to the ED symptomatic of chest pain and having at least one cardiac risk factor, but with no known CAD or past ACS. Factors that may affect QTc prolongation such as drugs, and electrolyte abnormalities which were not accounted for in most prior studies were excluded in the present study. Also important to note, is the interesting finding that BMI defined in our study as BMI>26 was also an independent risk factor for ACS and all cause mortality within 1 year for patients presenting with chest pain and at least one cardiac risk factor. Further studies are needed to explore this finding.

This study was limited to a single center and was retrospective. We could not control for patients who may have gone to other medical centers for occurrence of subsequent ACS within 1 year of follow up. Also QTc was not manually calculated but rather was obtained from the computer reported ECG on index ED visit. However, this does reflect real world care and offers an easy quick look predictor of future ACS and death risk for patients presenting to the ED with chest pain. 
In conclusion, QTc prolongation at ED presentation in patients with chest pain with at least one cardiac risk factor is an independent risk factor for occurrence of ACS or allcause mortality within 1 year. Whether this finding can be a potential add on feature to risk scores, such as TIMI GRACE or PURSUIT will require prospective studies to confirm and compare the predictive value of QTc interval prolongation in patients presenting to the ED with chest pain. $[13,14,15]$ 


\section{References:}

[1] Moss et al, Measurement of the QT interval and the risk associated with QT interval p prolongation: A review. , 26 August 1993, Pages B23-B25

[2] Bruyne et al, Prolonged QT interval predicts cardiac and all-cause mortality in the elderly. The Rotterdam Study European Heart Journal (1999) 20, 278-284

[3]Dekker JM, Schouten EG, Klootwijk P, Pool J, Kromhout D. Association between QT interval and coronary heart disease in middle-aged and elderly men. The Zutphen Study. Circulation 1994

[4]Robbins J, Nelson JC, Rautaharju PM, Gottdiener JS. The association between the length of the QT interval and mortality in the cardiovascular health study. Am J Med 2003;115:689-94.

[5]Schouten EG, Dekker JM, Meppelink P, Kok FJ, Vandenbroucke JP, Pool J. QT interval prolongation predicts cardiovascular mortality in an apparently healthy population. Circulation 1991;84:1516 -23.

[6]Helming et al. The prognostic value of the QT interval and QT interval dispersion in all-cause and cardiac mortality and morbidity in a population of Danish citizensEur Heart J, Vol. 19, September 1998 
[7]Montanez et al,. Prolonged QTc interval and risks of total and cardiovascular mortality and sudden death in the general population: a review and qualitative overview of the prospective cohort studies. Arch Intern Med. 2004 Sep 13;164(16):1796

[8]Goldberg RJ, Bengtson J, Chen ZY, Anderson KM, Locati E, Levy D.Duration of the QT interval and total and cardiovascular mortality in healthy persons (the Framingham Heart Study experience). Am J Cardiol 1991;67:55- 8

[9]Okin PM, Devereux RB, Howard BV, Fabsitz RR, Lee ET, Welty TK. Assessment of QT interval and QT dispersion for prediction of all-cause and cardiovascular mortality in American Indians: the Strong Heart Study. Circulation 2000;101:61-6

[10]Francisco L Gadaleta ${ }^{a}$, Susana C Llois ${ }^{a}$, Víctor A Sinisi $^{a}$, Juan Quiles ${ }^{b}$, Pablo Avanzas $^{c}$, Juan C Kaski Corrected QT Interval Prolongation: a New Predictor of Cardiovascular Risk in Patients With Non-ST-Elevation Acute Coronary Syndrome Rev Esp Cardiol. 2008;61:572-8. - Vol. 61 Num.06

[11]Jiménez-Candil J, Cruz González I, González Matas JM, Albarrán C, Pabón P, Moriñigo JL, et al. Short- and long-term prognostic value of the corrected QT interval in the non-ST elevation acute coronarysyndrome. J Electrocardiol. 2007;40: 180-7.

[12] Beinart et al. The QT Interval Is Associated With Incident Cardiovascular Events. The MESA Study. J Am Coll Cardiol. 2014;64(20):2111-2119. 
[13] A Conway Morris, D Caesar, S Gray, and A Gray. TIMI risk score accurately risk stratifies patients with undifferentiated chest pain presenting to an emergency department. Heart. 2006 Sep; 92(9): 1333-1334.

[14]Elbarouni B, Goodman SG, Yan RT, Welsh RC, Kornder JM, Deyoung JP, Wong GC, Rose B, Grondin FR, Gallo R, Tan M, Casanova A, Eagle KA, Yan AT. Validation of the Global Registry of Acute Coronary Event (GRACE) risk score for in-hospital mortality in patients with acute coronary syndrome in Canada. Am Heart J. 2009 Sep;158(3):392-9

[15] Brilakis ES, Wright RS, Kopecky SL, Mavrogiorgos NC, Reeder GS, Rihal CS, Gersh BJ, Williams BA, Clements IP. Association of the PURSUIT risk score with predischarge ejection fraction, angiographic severity of coronary artery disease, and mortality in a nonselected, community-based population with non-ST-elevation acute myocardial infarction. Am Heart J. 2003 Nov;146(5):811-8. 
Figure Legends

Figure 1: Kaplan-Meier log survival plot of heart rate corrected QT (QTc) interval prolongation and composite outcome of ACS and all cause mortality within 1 year, $p<.001$ 
Figure 1

$Q T \leq 460$
$Q T>460$

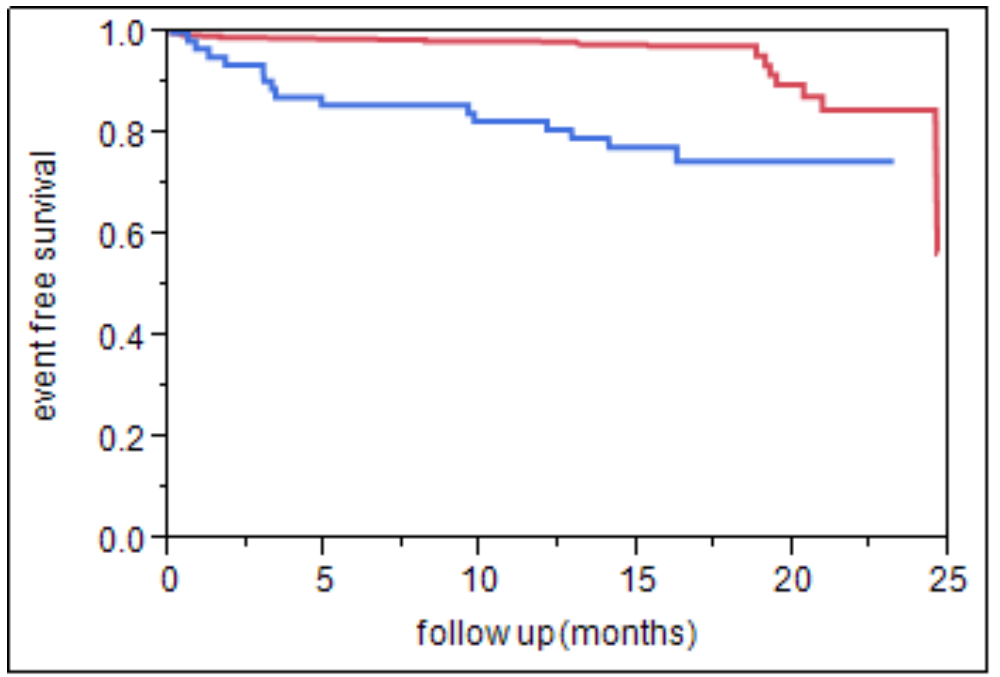


Table 1a. Baseline characteristics of the study population stratified by the QTC prolongation at baseline

\begin{tabular}{|c|c|c|c|}
\hline & $\begin{array}{l}\text { QTc } \leq 460 \\
\text { msec }\end{array}$ & $\begin{array}{l}\text { QTc }>460 \\
\text { msec }\end{array}$ & $p$ \\
\hline$n$ & 445 & 64 & \\
\hline Male Gender \% & 49 & 40.6 & 0.21 \\
\hline Age $>60 \%$ & 28.5 & 46.9 & 0.003 \\
\hline Hypertension \% & 59.3 & 81.2 & 0.0007 \\
\hline $\begin{array}{l}\text { Diabetes } \\
\text { Mellitus \% }\end{array}$ & 34.4 & 46.9 & 0.05 \\
\hline $\begin{array}{l}\text { Hyperlipidemia } \\
\%\end{array}$ & 30.2 & 45.3 & 0.015 \\
\hline $\begin{array}{l}\text { Family History } \\
\text { of CAD \% }\end{array}$ & 8.3 & 9.4 & 0.77 \\
\hline $\begin{array}{l}\text { Overweight } \\
\text { BMI >26\% }\end{array}$ & 68.8 & 67.2 & 0.78 \\
\hline Smoking \% & 60.1 & 57.8 & 0.72 \\
\hline
\end{tabular}


Table 1b. Survival Analysis (ACS or mortality within one year), Hazard Ratios with $95 \%$ confidence intervals

\begin{tabular}{|c|c|c|}
\hline & Univariate analysis & $\begin{array}{l}\text { Multivariate } \\
\text { analysis }\end{array}$ \\
\hline Age $>60$ & $2.14(1.10-4.15)$ & $1.03(0.47-2.21)$ \\
\hline Hypertension & $2.01(1.01-4.27)$ & $1.48(0.65-3.70)$ \\
\hline Diabetes Mellitus & $2.22(1.14-4.30)$ & $1.35(0.63-2.90)$ \\
\hline Hyperlipidemia & $3.12(1.61-6.13)$ & $2.26(1.08-4.88)$ \\
\hline $\begin{array}{l}\text { Family History of } \\
\text { CAD }\end{array}$ & $1.58(0.46-4.06)$ & $1.38(0.40-3.61)$ \\
\hline $\mathrm{BMI}>26$ & $2.03(0.99-4.58)$ & 2.55 (1.08-7.05) \\
\hline QTc $>460$ & $8.12(4.00-16.72)$ & $7.68(3.57-16.61)$ \\
\hline
\end{tabular}

†Adjusted for age $>60$, presence of hypertension, diabetes mellitus, hyperlipidemia family history of CAD, BMl>26 